\title{
The assessment-capable teacher: Are we all on the same page?
}

\author{
Beverley Booth, Mary F. Hill, and Helen Dixon
}

\begin{abstract}
The report Directions for Assessment in New Zealand (Absolum, Flockton, Hattie, Hipkins, \& Reid, 2009) envisages an "assessment capable" system where students are empowered to become selfregulated learners. This article explores the concept of assessment capability. It considers what it means to be an assessment-capable teacher in New Zealand, the lessons that have been learned in this area, and why the realisation of the assessment-capable student may be challenging. It examines the critical roles that teachers play in meeting three key conditions (Sadler, 1989) needed for students to acquire evaluative and productive knowledge and skills. Finally, it suggests ways that teachers may be supported to become assessmentcapable professionals.
\end{abstract}

\section{Introduction}

A review of assessment approaches in New Zealand resulted in the report Directions for Assessment in New Zealand: Developing Students' Assessment Capabilities (DANZ) (Absolum, Flockton, Hattie, Hipkins, \& Reid, 2009). The report was commissioned by the Ministry of Education to set out policy directions for assessment in New Zealand. In placing students' self-assessment at the heart of what teachers do, the advice in DANZ is consistent with current research findings in assessment (Absolum et al., 2009; Flockton, 2012). For example, the importance of student involvement in the assessment process is highlighted by Earl (2003), Hattie and Timperley (2007) and Sadler (2010). The central premise of DANZ is that "all young people should be educated in ways that develop their capacity to assess their own learning" (Absolum et al., 2009, p. 5). The focus of DANZ quite deliberately builds on existing Assessment for Learning (AfL) practices. AfL is defined as "the process of seeking and 
interpreting evidence for use by learners and their teachers to decide where learners are in their learning, where they need to go and how best to get there" (Assessment Reform Group, 2002, p. 2). Unfortunately, however, AfL is often interpreted in ways that fail to engage the learner in selfevaluative practices (Dixon, 2008; Marshall \& Drummond, 2006). The DANZ report subsequently informed the Ministry of Education position paper on assessment (Ministry of Education, 2010b), which presents a vision of system-wide assessment practices where assessment is at the heart of effective teaching and learning. Both DANZ and the Ministry of Education position paper on assessment share an aim of students becoming "assessment capable" learners.

Flockton (2012b) details the need for an assessment-capable system, without which the vision of the assessment-capable student is unlikely to be realised. As one of the authors of DANZ, Flockton highlights the challenge faced in his statement that: "It is one thing to propose a forwardthinking direction for assessment policy and practice in New Zealand; it is another to identify what is required for this to be realised" (p. 134). This statement mirrors Wiliam's (2006. p. 8) observation that just because "we know what needs to be done does not mean that we know how to do it". Both Flockton and Wiliam refer to practices which place the learner, their self-reflection, and their voice at the heart of the learning, with the aim of engendering pupil self-regulation. Their comments relate to the complexity of translating policy into classroom practice. This article considers what it means to be an assessment-capable teacher in New Zealand, the lessons that have already been learned in this area, and why the realisation of assessment capability may indeed be challenging.

\section{Assessment capable as a new term}

It can be questioned why a new term, unique to New Zealand, should be introduced. In recent times, the term assessment literacy (Popham, 2009; Stiggins, 1991) has often been used to describe the knowledge and skills which professionals need when assessing their pupils. Assessmentliterate professionals know what they are assessing and why (Popham, 2009; Stiggins, 2002). They know which assessment methods to use, know what can go wrong, communicate results effectively, and can 
maximise student motivation by involving them as partners (Stiggins, 1991). The term assessment literacy describes what teachers and other education professionals know and do, including the implementation of a range of formative assessment practices, but its usage does not always refer to student agency. Assessment-capable teachers have the curricular and pedagogical capability, and the motivation, to engender assessment capability in their students. The use of the term assessment capable distinguishes the New Zealand stance from other assessment systems where the student's own assessment capability may not be at the heart of the assessment process.

Assessment practices involve communication between people who may have varying degrees of assessment literacy. It is important that there is common understanding of language used, but in reality agreeing and interpreting common terminology is challenging (Black \& Wiliam, 1998). Since this article will refer extensively to the term assessment capable, it is important that this be defined. The term is widely and repeatedly used in DANZ, and is also mentioned in the Ministry position paper. A capability can be defined as "the ability to meet demands or carry out a task successfully ... A capability has an internal structure that includes knowledge, cognitive skills, practical skills, attitudes, emotions, values, ethics and motivation" (Absolum, 2006, p. 22). In the case of assessment capability, the "internal structure" detailed in DANZ requires the teacher to:

- take the lead in all assessment that students cannot manage without support ... in ways that encourage students to feel deeply accountable for their own progress and support them to become motivated, effective, self-regulating learners

- be knowledgeable about the curriculum and teaching

- [have] well developed assessment capabilities and the motivation to use these to forge learning partnerships with their students

- know how to gather the assessment information that other stakeholders require, and how to pass it on in ways that are consistent with, and supportive of, student learning

- [have] awareness of the effects of assessment on learners

- know exactly how an assessment should assist students to learn, and how to check whether it has done so

- [establish] a classroom climate where mistakes are seen as 
opportunities, and where shared conversations about the nature of learning are commonplace.

(Absolum et al., 2009, p. 24)

Much of this is not new and New Zealand teachers should be familiar with many of the sound assessment principles and practices detailed here. The distinguishing factor is the expectation that teachers will encourage students to feel deeply accountable for their own progress and support them to become motivated, effective, self-regulating learners.

DANZ describes what is meant by assessment capability, but concern is raised by Flockton (2012b) that the prime focus, namely the development of the student as a self-regulated learner, may be overlooked. In reality, 4 years after DANZ was published, my own informal inquiries suggest that many school-based professionals are currently unaware of the term assessment capable and its relationship to student self-assessment and self-regulated learners. This reflects Flockton's own informal inquiries, which suggest that school-based leaders do not interpret the Ministry of Education position paper (2010b) in the intended way, as there was a failure to recognise the need to develop assessment-capable students. It appears that, several years after the term assessment capable entered the discourse of assessment in New Zealand with the express intention of describing the deep, student-focused approach that was envisaged, the term itself has not yet entered the everyday assessment vocabulary of school-based professionals.

Currently, many decisions about assessment are made for students by adults (Absolum et al., 2009), with student involvement being either infrequent or involving "low-stakes" activities. The realisation of the assessmentcapable student will require norms of behaviour which encourage student autonomy and enable student agency during learning. This reflects Sadler's suggestion that there should be explicit provision for students to acquire evaluative and productive knowledge and skills, with the goal of facilitating "the transition from feedback to self-monitoring" (1989, p. 122). While implementing this may not be easy, Sadler provides three key conditions, to be met simultaneously, that could effect this shift. The students need to: understand what constitutes quality; have the requisite metacognitive skills to effectively evaluate their work; have strategies to draw on to modify their 
own work during its production. These three distinct conditions each need to be mindfully addressed by the assessment-capable teacher. In the spirit of the DANZ report, this article approaches these issues from the stance of student needs, reflecting on what the teacher will need to do to meet these needs. Additionally, it examines how the assessment-capable system will need to support these changes.

\section{Condition 1: The assessment-capable teacher helps students to understand what constitutes quality}

Hattie (2009) highlights the importance of the learning being visible to the teacher and the teaching being visible to the learner. To facilitate the independent skills of learners, teachers must be prepared to share their understanding of the requisite standard and what this looks like in practice. Only when this knowledge becomes transparent and is shared with learners can they learn to make their own judgements about the quality of their work. If teachers keep the knowledge of what constitutes the standard, learners' dependence on teachers is maintained. The ability and willingness of teachers to share their expert knowledge, and to construct learning environments where learners can gain and make use of these skills, is crucial (Black \& Wiliam, 1998; Sadler, 1989).

To become assessment-capable students, learners need the support of knowledgeable teachers. Teachers hold tacit or "guild" knowledge (Sadler, 1989) of what constitutes quality, constructed from professional learning, knowledge gleaned from actually carrying out assessments, and from interactions with others. To authentically share their understandings in the ways envisaged by the DANZ report, teachers need to enable their students to access, interpret, and use information which will help them to meet their learning goals. Both less-formal classroom assessment activities, which are embedded in the everyday learning of the classroom, and more-formal assessment tasks require this level of transparency. Students need to learn how to self- and peer assess, to act on feedback, and to access materials that detail criteria and exemplify quality.

In New Zealand, materials exist to aid teachers in making assessment judgements. For example, annotated exemplars of work assessed against the levels in The New Zealand Curriculum (Ministry of Education, 2007) 
are available in The New Zealand Curriculum Exemplars (Ministry of Education, 2003). The e-asTTle writing test has a rubric of level descriptors, referenced to exemplars that guide teacher judgements. Documents such as the Literacy Learning Progressions (Ministry of Education, 2010a) provide detailed descriptors, and the Reading and Writing Standards for Years 1-8 (Ministry of Education, 2009) similarly provide annotated examples of work, at different year levels, for reading, writing, and mathematics. All these materials, and more, are available online, including video clips. This plethora of materials has, however, been produced for a teacher audience.

Dixon (2008) observes that, despite much overseas research, in New Zealand research into actual teachers' practice has been sparse. Dixon calls for studies documenting, for example, how teachers and students use exemplars and criteria. Exemplars give students concrete examples, without which criteria and expectations can remain abstract and inaccessible to the learner (Sadler, 2009). While, in theory, students can compare their work to that in the exemplars (e.g., by contrasting a piece of writing with a levelled exemplar), the terminology used in the annotations is often challenging for a primary-school-aged student. Students need to understand the criteria, and teachers should beware of assuming that they know and understand terminology (Sadler, 2010). This means that teachers may need to adapt the existing resources, or create new materials, for pupil use.

Teachers need to be adept at evaluating children's work accurately to determine next steps in learning. For students to effectively use exemplars for self-assessment in relation to curriculum levels, teachers need to help them to deconstruct the criteria and descriptors, interpret what they mean, and apply them to real examples of work. Teachers will also need to model how to judge performance against success criteria or assessment criteria.

\section{Condition 2: The assessment-capable teacher helps students develop the metacognitive skills to evaluate their work}

Sadler makes the point that "if anything, the guild knowledge of teachers should consist less in knowing how to evaluate student work and more in knowing ways to download evaluative knowledge to students" (1989, p. 141). Teachers need to help students develop the requisite metacognitive 
skills to effectively evaluate their work. Successful students have agency and take charge of their own learning (Hacker, Dunlosky, \& Graesser, 2009). While less-successful students may not use metacognitive strategies effectively, these skills can be taught, and this can lead to improvement in achievement (Baker, 2008). When students are encouraged to practise thinking about their own learning they are more able to discuss their understanding with others (Absolum et al., 2009; Black \& Wiliam, 1998; Perry \& Rahim, 2011; Zimmerman \& Schunk, 2011), thus opening the way to self- and peer-assessment practices.

Metacognition is the process of thinking, or learning, about one's own learning. It is concerned with active monitoring and regulation of the cognitive processes and is central to the ability to plan, problem solve, and evaluate (Flavell, 1979). It includes knowledge about the skills, strategies, and resources needed to carry out a task effectively (Baker, 2008). Effective learners create internal feedback and cognitive routines when they are engaged in academic tasks (Bruner, 1996; Hattie \& Timperley, 2007). Just as in any other area of learning, however, some students need more help and assistance than others. Learning to use metacognitive strategies successfully does not happen quickly (Baker, 2008) and students need support, time, and opportunities, in the context of their learning, to master these self-reflective skills.

Hattie and Timperley (2007) identify two major aspects of self-reflection: first, self-appraisal, whereby learners review and evaluate their abilities, knowledge states, and cognitive strategies; and second, self-management, where learners monitor and regulate their behaviour and planning, correct mistakes, and use fix-up strategies. Thus, self-reflection requires both thought and action. Aligned with the ability to do these things, for both student and teacher, is also the motivation to do so.

Teachers need to work with awareness that learners who are asked to critically appraise their own work need to do so in a safe, learning-focused environment, where mistakes are seen as opportunities for growth. This requires sensitive introduction and usage, as for some students selfevaluation may impart a sense of failure and reduce self-confidence (Wragg, 1997). Learning can be an emotional experience, with the feelings of learning occupying the position where attraction and repulsion 
overlap (Claxton, 1999). Although new learning is often exhilarating, the possibility of incompetence is threatening and may trigger an urge to withdraw to protect oneself.

Professional learning opportunities for teachers to explicitly learn how to develop the metacognitive skills of their students would be a positive move. However, there is a difference between the incorporation of metacognitive reflection into the culture of the classroom and engagement in thinking-skills activities once a week. Even when these deeper practices are apparent in the classroom, variance in the effect on the student can be detected because the actual climate of the classroom and its perceived rules also determine the outcomes for individual students (Torrance \& Pryor, 1998).

Simply sharing assessment knowledge with students in supportive classrooms will not, in itself, promote student self-evaluation. Nor is it enough to leave students alone to self-assess. Students need to be provided with sustained and supported experiences in questioning and improving their work (Gipps \& MacGilchrist, 1999; Sadler, 1989), as they need specific language to describe, discuss, and evaluate their learning (Absolum et al., 2009; Moss, Brookhart, \& Long, 2013). Clearly, assessment-capable teachers need to have this language themselves, understand the concepts they intend to develop, have access to resources to help teach the skills, and be able to make space in their day to do so. Teachers will need to model effective problem-solving approaches (Black $\&$ Wiliam, 1998), and be willing and able to be learners themselves.

\section{Condition 3: The assessment-capable teacher helps students learn strategies to modify their own work}

Conditions 1 and 2 detail the need for the assessment-capable teacher to develop a safe pedagogical learning environment where students can take responsibility for the learning. Within this environment, the student has access to materials which exemplify expectations and quality and is helped to develop the requisite metacognitive skills to evaluate their own learning. Condition 3 is concerned with the need for students to learn how to monitor and improve the quality of their work during and after its production. For this learning to take place, explicit teaching and 
provision within the school day is required. In order for self-evaluation to have an impact on emerging pieces of work, the student needs to be able to draw on a range of possible ways to improve their work during its construction (Sadler, 2009) and to identify where and when to make these improvements. The assessment-capable teacher needs to teach students how to critically appraise work, as such critical appraisal helps students not only to understand what quality looks like, but also to expand their understanding of ways to improve their own work (Davies \& Hill, 2009; Hattie \& Timperley, 2007).

Peer assessment is a key activity through which students can learn to make evaluative judgements by appraising the work of others. However, the teacher needs to teach students how to engage purposefully in selfand peer assessment to provide students with practical experience and conceptual knowledge (Sadler, 2010). Without this explicit teaching, much of the feedback that students receive from their peers may be wrong (Nuthall, 2007). Sadler identifies three critical elements of the process. First, identifying whether the task specification has been met; secondly, assessing the quality of the overall piece; and finally backing up the judgement with reference to criteria. This process is of particular value when assessing complex work, such as writing, where quality is often "the degree to which a work comes together as a whole to achieve its intended purpose" (Sadler, 2010, p. 544). Reference to actual pieces of work is important because it is often easier to recognise quality than to describe it in the abstract or attempt to identify it through lists of criteria, where "not uncommonly, something significant is lost" (Sadler, 2010, p. 544).

Assessment-capable teachers plan to provide a variety of exemplars which illustrate what is expected of the students (Davies \& Hill, 2009). They provide opportunities for evaluative conversations. They encourage students to use this information to improve their work during its production. In this way, students can actively develop a concept of quality, they can evaluate their work, and they can make, and act on, decisions concerning the improvement of their work. 


\section{The critical role of the assessment-capable teacher}

Classroom teachers, as "the orchestrators, encouragers, interpreters and mediators of learning" (Absolum et al., 2009, p. 24) clearly have a key role in meeting Sadler's three conditions, in order to develop student assessment capability. Not only does this require extensive understanding of assessment, but of pedagogy (Bell \& Cowie, 2001; Sadler, 1998), curriculum, subject knowledge, metacognition, and the students. For many teachers, this way of working with their pupils will require deep changes to their practice, which cannot be a "quick fix" (Black \& Wiliam, 1998). Teacher assessment capability is a complex web of "knowledge, cognitive skills, practical skills, attitudes, emotions, values, ethics and motivation" (Absolum, 2006, p. 22). Learning to be an assessment-capable teacher is a complex process, and preparing teachers to be assessment capable is likely to be challenging (Hill, Cowie, Gilmore, \& Smith, 2010).

The DANZ report distinguishes between professional learning that backgrounds assessment, and that which foregrounds assessment. In 2002, a Ministry of Education teacher development programme, entitled "Assess to Learn" (AtoL), was introduced in New Zealand, to meet the Ministry of Education's aims of:

- improved student learning and achievement

- shift in teachers' knowledge and assessment practice

- development of coherence between assessment processes, practices and systems ... [to] promote better learning

- a culture of continuous school improvement.

(Flockton, 2012b, p. 10)

About 35 percent of primary schools (Flockton, 2012b) have engaged with the programme. Before entering the programme, many schools have engaged in professional learning which has included elements of assessment. However, few demonstrate high levels of assessment capability, suggesting that teachers do not "catch" assessment capability from other professional learning (Absolum et al., 2009, p. 27). In a review of the AtoL contract, Poskitt and Taylor (2007) found that many teachers needed continued support and encouragement to reflect with their students into a second year, which suggests that even when AfL is foregrounded it is still difficult to implement in the classroom. While the involvement 
of students in making their own learning decisions has been a focus for professional learning, the Education Review Office report Working with National Standards within The New Zealand Curriculum (Education Review Office, 2010) found that only 30 percent of primary schools had well-established AfL practices. There is an ongoing need for support and professional learning regarding assessment in general, and specifically for student assessment capability and the use of assessment materials and tools to support them.

\section{How might assessment capability be developed in practising teachers?}

Practising teachers have existing knowledge and established practices in assessment. There is a potential disconnect between research and the practical application of that research to teaching, where new ideas could be viewed as impractical, or not in line with the teacher's own ways of working (Torrance \& Pryor, 2001). There is also a danger that, where theoretical constructs are not made apparent, teachers may "overassimilate" new ideas, implementing some aspects, but with a lack of knowledge or understanding of the principles which underpin the original theory (Timperley, Wilson, Barrar, \& Fung, 2007). Torrance and Pryor find that teachers need the opportunity to investigate and reflect on their own classroom practices, and relate them to theories of learning. The use of an analytical framework, as a precursor to teachers' engagement in their own action research, can help provide the vocabulary and means to enable teachers to determine their stance on assessment and use their own experiences to develop "practical arguments" (Fenstermacher, 1994). To do this, teachers will require the time and mental space to analyse their practice and access educational theory, enabling critical analysis of their own practice and the development of new ideas, a culture where teacher research and development are enabled. In fact, The New Zealand Curriculum presents a view of teaching as inquiry, and it is feasible that teachers inquire into their teaching and learning practices. They will need support from facilitators, mentors, and senior leaders who understand these practices and have the theoretical knowledge to be assessment capable themselves (Hill, 2011). 
Black and William (1998) compare what goes on in the classroom to the inside of a "black box". The black box is part of a system where inputs (e.g., policy, tests, and resources) are fed in and outputs (e.g., better test results) follow. They argue that many reform items are not aimed directly at supporting teachers to make "the inside work better", and indeed some of the inputs may be counter-productive and actually make it harder to raise standards. Black and Wiliam state that "the overarching priority has to be to promote and support change within the classroom" (p. 9) and recommend practitioners themselves collaborate to work out the answers to the practical questions that the research raises, in ways that "make sense to their peers in ordinary classrooms". They make clear that "this will only come about if each teacher finds his or her own ways of incorporating the lessons and ideas ... into his or her own patterns of classroom work ... through sustained programmes of professional development and support" (Black \& Wiliam, 1998, p. 10). However, this is not to suggest that teachers can, or should, do this without systemic involvement. Without this support, AfL practices are at risk of becoming "idiosyncratic to particular teachers and classrooms" (Moss, Brookhart, \& Long, 2013, p. 205).

School leaders have a pivotal role to play. They need to guide and support teachers and create assessment-capable cultures where the focus is on creating a respectful and responsive learning environment, rather than on evaluation (Hill, 2011; Moss et al., 2013). It is not enough to simply give materials or resources to teachers and conclude that teachers who do not use them are obstacles to change (Moss et al., 2013). Assessmentcapable leaders need to have a deep understanding of AfL so that they can recognise, understand, and gauge the effectiveness of AfL practices in their schools (Hill, 2011; Moss et al., 2013). School leaders also aid adoption through consideration of the way time, resources, and support are managed (Hill, 2011).

\section{Why is the development of assessment capability likely to be challenging?}

To realise the vision of the assessment-capable student, teachers will need to enhance, or change, their teaching, learning, and assessment practices. 
This may be problematic given that experienced teachers often have good teaching reputations, based on tried and tested methodologies, which are underpinned by deeply held beliefs. While the use of AfL practices promises great gains in learning (Black \& Wiliam, 1998), research shows that classroom practices which engender pupil autonomy are far from easy to implement, because they involve changing deeply ingrained routines and practices (Sadler, 1989; Wiliam, 2006). This is because the locus of control changes when student AfL is implemented authentically (Earl, 2003; James \& Pedder, 2006), and it requires teachers to rethink what effective learning is, and their role in bringing it about (James, 2006). The challenge in making this shift in control is widely acknowledged (Dixon, Hawe, \& Parr, 2011; Marshall \& Drummond, 2006; Poskitt \& Taylor, 2007). In keeping with the thinking of Black and Wiliam (1998), this research makes clear that such practices cannot be simply bolted on, but rather require a significant shift in roles and responsibilities, and the need to go beyond the "application of certain procedures" (Marshall \& Drummond, 2006, p. 135) into a deeper practice.

Marshall and Drummond (2006), members of the Learning How to Learn Project team (LHTL), noted that, in translating the principles of AfL into a procedural model which could be disseminated to help teachers introduce these practices into their classrooms, the process often became somewhat rule bound and static. Such practice has been described as following the letter of AfL. Distinguishing between those teachers who adhered to the letter of the procedures and those who embodied the underlying principles of a social-constructivist pedagogy leading to pupil autonomy, Marshall and Drummond found that only a few teachers were able to capture what they termed the spirit of AfL. The danger with a procedural model is that practices become "caricatured as merely another set of unexamined practical classroom strategies that teachers can use off the shelf, across all contexts, and without reference to educational values or beliefs" (James \& Pedder, 2006, p. 110).

A similar picture emerged in New Zealand. Dixon (2008) found that while teachers had incorporated the more mechanistic AfL practices, such as sharing learning intentions and success criteria, most remained in control of the feedback process. For a small group, who Dixon termed empowerers, teachers and students were more likely to work together, 
in ways more cogent with assessment capability, and engage in learning and feedback conversations. However, even within this group there were variations, and Dixon concluded that only a small percentage were actually enacting the underlying principles, and none had fully mastered this complex discourse.

In theory, student self-evaluation practices have become more widespread; however, there is much evidence which indicates they are difficult to implement consistently and effectively within the classroom. There is variance in the extent to which professional learning in this area is applied in the classroom (Dixon, 2008; Dixon et al., 2011; Hill et al., 2010; Poskitt \& Taylor, 2007). Teachers may also need continued support, as part of their professional development, to embody the deeper principles of student self-regulation (Poskitt \& Taylor, 2007).

It is generally accepted that the adoption of new practices is dependent on teacher beliefs (see, for example, Guskey, 1999; Timperley et al., 2007). However, this is a complex arena. Research has examined the extent to which AfL practices are adopted in the classroom internationally (James \& Pedder, 2006; Torrance \& Pryor, 1998), and in New Zealand (Dixon, 2008; Hill, 2000; Poskitt \& Taylor, 2007). Furthermore, there is evidence that teachers may only engage superficially with new practices when their beliefs and values do not align with the underlying principles of the pedagogy (Dixon, 2008; Marshall \& Drummond, 2006); that teachers experience a dilemma between what they believe and what they are capable of doing in practice to implement new practices (Dixon, 2008; James \& Pedder, 2006); and that teachers may adopt summative practices, despite their belief in formative assessment and child-centred pedagogy, owing to the need for accountability (Hill, 2000). This latter finding is reflected in recent research which suggests substantial changes to assessment practices are taking place in response to the implementation of the New Zealand National Standards (Thrupp, 2013).

\section{Changing practice by changing policy}

The DANZ report highlights the need for an assessment-capable system where all parts are aligned and work together to realise the vision of assessment-capable students. This requires recognition and awareness of 
the complexity of the task facing the teacher in the classroom (Flockton, 2012a). Black and Wiliam make the point that teachers need to be both "provoked and supported in trying to establish new practices in formative assessment" (1998, p. 5).

Flockton (2012a) calls for assessment capability to be adopted into education practice, first through changes in policy. However, he warns that imposing change from above often meets with "counterproductive resistance" (p. 145), so the means by which the assessment-capable system will enable teachers to become assessment capable is an important issue. Flockton acknowledges that enactment of assessment policy in schools is often driven through regulation and suggests that the National Education Guidelines be used to provide greater direction to schools on quality assessment practices. These guidelines form part of the legislative framework within which schools in New Zealand operate. The National Educational Goals, The New Zealand Curriculum (Ministry of Education, 2007), and the National Standards (Ministry of Education, 2009) are part of these guidelines.

Research shows, however, that the intersection of policy and practice can be challenging. In an evaluation of the Assessment is for Learning (AifL) programme in Scotland, Hutchinson and Hayward (2005) describe the process of bringing together research, policy, and practice as both hazardous and uncertain. The AifL programme, in a similar vein to the DANZ report, aims to support teachers to enable students to think about their learning, decide on next steps, and make moves to further their own progress. In common with DANZ, a supportive national policy framework which would provide appropriate tools and guidance to schools was envisaged. Hutchinson and Hayward liken the realisation of this to navigating a swamp, "an endeavour not for the faint-hearted, those who lack energy or who are unwilling to persevere" (2005, p. 244). Two major challenges were identified. These were the tension between AfL and assessment for accountability and changes that were performed to the letter, rather than in the spirit of AfL.

In New Zealand, current regulation and guidance documents already support AfL practices; however, the central role of the student's own assessment capability is not generally apparent. For example, the current 
New Zealand Teacher Registration Criteria (New Zealand Teachers Council, 2010) detail the need for teachers to analyse assessment information to identify progress and ongoing learning needs of learners and use assessment information to give regular and ongoing feedback to guide and support further learning. They encompass an interpretation of assessment where the teacher is in control and holds the knowledge of what constitutes success and quality, rather than the more studentcentred approach envisaged in DANZ. The assessment-capable teacher will need to move beyond these criteria if they are to realise the vision of assessment-capable students.

In principle, the development of assessment-capable students who are responsible for their own learning is also already supported by The New Zealand Curriculum (Ministry of Education, 2007), which views teaching as inquiry and "encourages all students to reflect on their own learning processes and to learn how to learn" (p. 9). Through the development of key competencies students "actively seek, use and create knowledge" (p. 12), develop a "can do" attitude, and see themselves as capable learners. Additionally, the New Zealand National Standards state that it is important that teachers and students know the purpose of the assessment, what is being assessed and why, and know how to use what is learnt from the assessment activity to improve teaching and learning.

The Ministry position paper on assessment (2010b) acknowledges that the development of an assessment-capable system, as envisaged in the DANZ report, will require a significant step up in assessment capability across the sector. Earl (2003) uses the term assessment as learning to describe a self-reflective culture which is apparent at all levels of the system, including the aptitude and willingness of teachers to engage in self-reflective practice to determine how well they are assisting their students to be independent, self-reflective learners. In such a system, the primary assessor is the student and the key purpose is "self-monitoring and self-correction or adjustment" (Earl, 2003, p. 26). This rethinking of learning and teaching in relation to assessment practices is part of a wider move to improve teaching and learning, and also to better meet the perceived needs of learners in the 21 st century. Earl maintains that classrooms where assessment is viewed as part of learning are very different places to those with a traditional view of assessment. In part, 
this difference is due to a shift in power, with assessment as learning described as "a personal, iterative and evolving conversation in which teachers are assessing and describing performance in ways that are useful to others, who will make their own decisions about what to do next" (Earl, 2003, p. 45).

\section{Conclusion}

The DANZ report presents a forward-thinking vision for teaching and learning in New Zealand, through the system-wide adoption of policies and practices that support the development of assessment-capable students. Despite time and money being spent on AfL policy, practices, and professional development, the deeper principles which enable assessment capability in our students remain relatively elusive. Although the focus of the DANZ report is the student, classroom teachers have crucial roles to play, for example in meeting Sadler's (1989) conditions. Assessmentcapable teachers must draw on a complex and challenging array of "knowledge, cognitive skills, practical skills, attitudes, emotions, values, ethics and motivation" (Absolum, 2006, p. 22) to meet the emerging needs of their students. Flockton (2012) is right to be concerned that school leaders failed to identify the key focus of the assessment-capable student, for if teachers are to be effectively supported in this endeavour it is essential that what actually goes on in the classroom is understood by other members of the envisaged assessment-capable system.

Classroom-based research which gives a voice to both teachers and students as they journey toward assessment capability could provide valuable insight and answer the question "What are the powerful influences on teacher and student adoption of practices leading to assessment capability?" A further question of "How can teacher inquiry assist in the realisation of assessment capability in New Zealand?" aligns with The New Zealand Curriculum's view of teaching as inquiry. Torrance and Pryor (2001) present teacher inquiry as a powerful way to encourage teachers to engage with the deeper practices of AfL, and similarly Black and Wiliam (1998, p. 10) assert that the requisite changes will only come about if teachers find their "own ways of incorporating the lessons and ideas". The key to assessment capability surely lies at the classroom door. 


\section{References}

Absolum, M. (2006). Clarity in the classroom: Using formative assessment, building learning-focused relationships. Auckland: Hachette Livre.

Absolum, M., Flockton, L., Hattie, J., Hipkins, R., \& Reid, I. (2009). Directions for assessment in New Zealand (DANZ): Developing students'assessment capabilities. Wellington: Ministry of Education.

Assessment Reform Group. (2002). Assessment for learning: 10 principles. Retrieved from http://www.aaia.org.uk/content/uploads/2010/06/Assessment-for-Learning10-principles.pdf

Baker, L. (2008). Metacognition in comprehension instruction: What we've learned since NRP. In C. Block \& S. Parris (Eds.), Comprehension instruction: Researchbased best practices (pp. 65-79). New York: The Guilford Press.

Bell, B., \& Cowie, B. (2001). Formative assessment and science education. Dordrecht, Netherlands: Kluwer Academic Press.

Black, P., \& Wiliam, D. (1998). Inside the black box: Raising standards through classroom assessment. London: King's College London, School of Education.

Bruner, J. S. (1996). The culture of education. Cambridge, MA: Harvard University Press.

Claxton, G. (1999). Wise-up: The challenge of lifelong learning. London: Bloomsbury.

Davies A., \& Hill, M. (2009). Making classroom assessment work. Wellington: NZCER Press.

Dixon, H. (2008) Feedback for learning; Deconstructing teachers' conceptions and use of feedback. Unpublished doctoral thesis, The University of Auckland.

Dixon, H., Hawe, E., \& Parr, J. (2011). Enacting assessment for learning: the beliefs practice nexus. Assessment in Education: Principles, Policy \& Practice, 18(4), $365-379$.

Earl, L. (2003). Assessment as learning: Using classroom assessment to maximize student learning. Thousand Oaks, CA: Corwin Press.

Education Review Office. (2010). Working with the National Standards within The New Zealand Curriculum. Wellington: Author.

Fenstermacher, G. (1994). The knower and the known: The nature of knowledge in research on teaching. Review of Research in Education, 20, 3-56.

Flavell, J. H. (1979). Metacognition and cognitive monitoring: A new area of cognitive-developmental inquiry. American Psychologist, 34(10), 906.

Flockton, L. (2012a). Commentary: Directions for assessment in New Zealand. Assessment Matters, 4, 129-149.

Flockton, L. (2012b). The development of the student assessment system in New Zealand (Systems Approach for Better Education Results (SABER) country report No. 5). 
Retrieved from http://documents.worldbank.org/curated/en/2012/01/16552609/ development-student-assessment-system-new-zealand

Gipps, C., \& MacGilchrist, B. (1999). Primary school learners. In P. Mortimer (Ed.), Understanding pedagogy and its impact on learning (pp. 46-68). London: Paul Chapman.

Guskey, T. (1999). Evaluating professional development. Thousand Oaks, CA: Corwin Press.

Hacker, D. J., Dunlosky, J., \& Graesser, A. C. (2009). Handbook of metacognition in education. New York: Routledge.

Hattie, J. (2009). Visible learning: A synthesis of over 800 meta-analyses relating to achievement. Oxford: Routledge.

Hattie, J., \& Timperley, H. (2007). The power of feedback. Review of Educational Research 77(1), 81-112.

Hill, M. (2000). Remapping the assessment landscape: Primary teachers reconstructing assessment in self-managing schools. Unpublished doctoral thesis, University of Waikato.

Hill, M. (2011). 'Getting traction': Enablers and barriers to implementing Assessment for Learning in secondary schools, Assessment in Education: Principles, Policy \& Practice, 18(4), 347-364.

Hill, M., Cowie, B., Gilmore, A., \& Smith, L. (2010). Preparing assessment-capable teachers: What should pre-service teachers know and be able to do? Assessment Matters, 2, 43-64.

Hutchinson, C., \& Hayward, L. (2005). The journey so far: Assessment for learning in Scotland. The Curriculum Journal, 16(2), 225-248.

James, M. (2006). Assessment teaching and theories of learning. In J. Gardner (Ed.), Assessment and learning (pp. 47-60). London: Sage.

James, M., \& Pedder, D. (2006). Beyond method: Assessment and learning practices and values. The Curriculum Journal, 7(2), 109-138.

Marshall, B., \& Drummond, M. J. (2006). How teachers engage with assessment for learning: Lessons from the classroom. Research Papers in Education, 21(2), 133-149.

Ministry of Education (2003). The New Zealand curriculum exemplars. Wellington: Learning Media.

Ministry of Education. (2007). The New Zealand curriculum. Wellington: Learning Media.

Ministry of Education. (2009). Reading and writing standards for years 1-8. Wellington: Learning Media.

Ministry of Education. (2010a). The literacy learning progressions. Wellington: Learning Media. 
Ministry of Education. (2010b). Ministry of Education position paper: Assessment (schooling sector). Wellington: Learning Media.

Moss, C., Brookhart, S., \& Long, B. (2013). Administrators' roles in helping teachers use formative assessment information. Applied Measurement in Education, 26(3), 205-218.

New Zealand Teachers Council. (2010). Registered teacher criteria handbook 2010. Wellington: Author. Retrieved from http://www.teacherscouncil.govt.nz/rtc http:// www.teacherscouncil.govt.nz/rtc/

Nuthall, G. (2007). The hidden lives of learners. Wellington: NZCER Press.

Perry, N. E., \& Rahim, A. (2011). Studying self-regulated learning in classrooms. In Zimmerman, B. J. \& Schunk, D. H. (Eds.), Handbook of self-regulation of learning and performance (pp. 122-136). New York: Routledge.

Popham, W. J. (2009). Assessment literacy for teachers: Faddish or fundamental? Theory Into Practice, 48(1), 4-11.

Poskitt, J. M., \& Taylor, K. (2007). Assess to learn professional development: Impact on teacher learning. Palmerston North: Massey University.

Sadler, D. (1989). Formative assessment and the design of instructional systems. Instructional Science, 18, 119-144.

Sadler, D. R. (1998). Formative assessment: Revisiting the territory. Assessment in Education: Principles, Policy and Practice, 5(1), 77-84

Sadler, D. R. (2009). Transforming holistic assessment and grading into a vehicle for complex learning. In G. Joughin (Ed.), Assessment, learning and judgement in higher education (pp. 45-64). New York: Springer.

Sadler, D. R. (2010). Beyond feedback: Developing student capability in complex appraisal. Assessment and Evaluation in Higher Education, 35(5), 535-550.

Stiggins, R. J. (1991). Assessment literacy. The Phi Delta Kappan, 72(7), 534-539.

Stiggins, R. J. (2002). Assessment crisis: The absence of assessment for learning. Phi Delta Kappan, 83(10), 758-765.

Thrupp, M. (2013). Research, analysis and insight into National Standards (RAINS) Project: Second Report: Understanding New Zealand's very local National Standards. Retrieved from http://www.education2014.org.nz/wp-content/ uploads/2012/07/RAINS-Report-20130510.pdf

Timperley, H., Wilson, A., Barrar, H., \& Fung, I. (2007). Teacher professional learning and development: Best evidence synthesis iteration (BES). Wellington: Ministry of Education.

Torrance, H., \& Pryor, J. (1998). Investigating formative assessment: Teaching, learning and assessment in the classroom. Buckingham, UK: Open University Press.

Torrance, H., \& Pryor, J. (2001). Developing formative assessment in the classroom: Using action research to explore and modify theory. British Educational Research Journal, 27(5), 615-631. 
Wiliam, D. (2006, 11 July) Does assessment hinder learning? Paper presented at the ETS Europe Breakfast Seminar. Retrieved from http://www.decd.sa.gov.au/ adelaidehills/files/links/williams_speec_1.pdf

Wragg, E. (1997). Assessment and learning. London: Routledge.

Zimmerman, B. J., \& Schunk, D. H. (Eds.). (2011). Handbook of self-regulation of learning and performance. New York: Routledge.

\section{The authors}

Beverley Booth is a part-time doctoral candidate at the University of Auckland. Prior to immigrating to New Zealand in 2009 she had a long career in education in England, including a number of years as a primary headteacher. She has now returned to her great love of classroom teaching. Her interest in AfL began in the 1990s, and since then she has worked with many teachers to introduce reflective practices into the classroom. She aims to be an assessment-capable teacher.

Email: bboo676@aucklanduni.ac.nz

Mary Hill is an associate professor in the Faculty of Education at the University of Auckland. Her research and teaching spans educational assessment, practitioner inquiry, and assessment learning through teacher education.

Helen Dixon is a principal lecturer in the Faculty of Education. Her teaching and research interests are focused on assessment for learning, feedback and how teacher beliefs, including their efficacy beliefs, influence assessment practice. 